Conde-Sala JL, Reñé-Ramírez R, Turró-Garriga O, Gascón-Bayarri J, CampdelacreuFumadó J, Juncadella-Puig M, Rico-Pons I, Garre-Olmo J. Severity of dementia, anosognosia and depression in relation to the quality of life of patients with Alzheimer's disease: discrepancies between patients and caregivers. American Journal of Geriatric Psychiatry, 2014; 22(2): 138-147.

DOI: $10.1016 /$ j.jagp.2012.07.001

\title{
Severity of dementia, anosognosia and depression in relation to the quality of life of patients with Alzheimer's disease: discrepancies between patients and caregivers
}

Josep L. Conde-Sala, Ph.D. ${ }^{1}$, Ramón Reñé-Ramírez, Ph.D. ${ }^{2}$, Oriol Turró-Garriga, B.Psych. ${ }^{3}$, Jordi Gascón-Bayarri, M.D. ${ }^{2}$, Jaume Campdelacreu-Fumadó, Ph.D. ${ }^{2}$, Montserrat Juncadella-Puig, Ph.D. ${ }^{2}$, Imma Rico-Pons, M.D. ${ }^{2}$, Josep Garre-Olmo, Ph.D. ${ }^{3,4}$

\author{
Institutional affiliations \\ ${ }^{1}$ Faculty of Psychology, University of Barcelona (Barcelona, Spain) \\ ${ }^{2}$ Dementia Unit, Department of Neurology, Bellvitge University Hospital (Hospitalet de \\ Llobregat, Spain) \\ ${ }^{3}$ Research Unit, Santa Caterina Hospital, Institut d'Assistència Sanitària (Salt, Spain) \\ ${ }^{4}$ Department of Psychology, University of Girona (Girona, Spain)
}

\author{
Author for correspondence \\ Josep Lluís Conde-Sala, University of Barcelona \\ Passeig Vall d'Hebron, 171 --08035 Barcelona (Spain)-- \\ E-mail: jllconde@ub.edu; Tel. (34) 9331258 14; Fax: (34) 934021368
}

Funding: This study was conducted within the framework of the project Assessing perceptions of patient quality of life in patients with Alzheimer's disease and their family caregivers over a two-year period, funded by Spain's Ministry of Science and Innovation (reference PSI2010-19014). No Disclosures to Report 


\begin{abstract}
Objective: To investigate the factors associated with discrepancies between patient and caregiver reports of the quality of life of patients (QoLp) with Alzheimer's disease (AD). Methods: Cross-sectional analytic study of 141 patients and their caregivers. The instruments used were the Quality of Life in AD (QoL-AD), the Global Deterioration Scale (GDS), the Geriatric Depression Scale (GDS-d) and the Anosognosia Questionnaire-Dementia (AQ-D). Differences were analyzed according to GDS stage. A linear regression analysis was conducted using the difference between the absolute QoLp scores of patients and caregivers. A cluster analysis involving the patient variables was then performed. Results: The discrepancy between patient and caregiver QoLp ratings increased in line with GDS stages $\left(\chi^{2}(2)=8.7, p\right.$ $=0.013)$. In the regression model $\left(\mathrm{F}[7,133]=16.6, \mathrm{p}<0.001 ; \mathrm{R}^{2}=0.477\right)$, discrepancies in QoLp reports were associated with greater anosognosia, less depression and a better cognitive status in patients, as well as with female gender among caregivers. The cluster analysis showed that patients with the lowest ratings of QoLp had a better cognitive status, more depression and less anosognosia. Conversely, the highest ratings were given by patients with a poorer cognitive status, less depression and greater anosognosia. Conclusions: The factors associated with greater discrepancies between patient and caregiver ratings of QoLp were severity of dementia, anosognosia, depression and cognitive status in patients, and female gender in caregivers. In patients with advanced dementia, greater anosognosia leads to more positive ratings in QoLp and complementary observations are required.
\end{abstract}

Key words: Quality of life, depression, anosognosia, severity of dementia, patients, caregivers. 
The assessment of quality of life is now widely included in clinical guidelines for the treatment of patients with dementia. Indeed, the Group for Harmonization of Dementia Drug Guidelines and the Alzheimer's Society (1) recommend that not only the patient's but also the relatives' and professionals' perceptions of the patient's quality of life be considered when evaluating the effectiveness and appropriateness of therapeutic interventions.

In recent years an increasing number of studies have examined the factors related to the perceived quality of life of patients (QoLp) with Alzheimer's disease. (AD) This research has shown that in patients higher depression scores, (2-4) the presence of behavioral disorders (57) and greater functional deficits $(8,9)$ all have negative effects on QoLp. Among caregivers, poorer ratings of QoLp have been shown to be associated with functional deficits $(10,11)$ and behavioral disorders $(3,9)$ in the patient and with burden $(3)$ and depression $(12,13)$ in the caregiver. Some authors have also reported that perceptions of QoLp are affected by sociodemographic and contextual factors such as the caregiver's gender (14), his or her relationship to the patient, (15-17) the patient's place of residence $(2,3)$ or the environmental conditions. $(18)$

Although the assessment of QoLp may be a valid and reliable indicator at any stage of the disease there are certain aspects which require careful consideration. One of the most important in this regard concerns the large discrepancy between patient and caregiver reports of quality of life, $(3,19)$ this being particularly notable as the severity of dementia increases; (12-20) other factors to consider in this regard are the influence of depression (21) and reduced awareness of deficits (anosognosia) in the patient. (22-26)

In light of the above the aims of the present study were as follows: 1) to determine the influence of severity of dementia, depression and anosognosia as regards the discrepancies between patient and caregiver reports of QoLp; and 2) to identify specific groups of patients associated with these discrepancies. 


\section{METHODS}

\section{Design and study population}

Design: The design was an observational, cross-sectional and analytic study.

Study population: A consecutive sample was recruited from among out-patients seen at the Dementia Unit of the Neurology Service of the Bellvitge University Hospital (Hospitalet de Llobregat, Spain). They were all diagnosed as either AD according to DSM-IV (Diagnostic and Statistical Manual of Mental Disorders) criteria (27) or probable AD according to NINCDS-ADRDA (National Institute of Neurological and Communicative Disorders and Stroke / Alzheimer's Disease and Related Disorders Associations) criteria, (28) and had a score on the Mini-Mental State Examination (MMSE) (29) of between 10 and 28. The sample also comprised their respective family caregivers. The main caregiver was defined as the person who was responsible for helping the patient with activities of daily living (ADL). Patients were excluded if they had severe communication problems that prevented them from responding adequately to the assessment questions. The study was approved by the hospital's Clinical Research Ethics Committee.

\section{Instruments}

Clinical and socio-demographic data. Socio-demographic data for patients and caregivers were gathered using an ad hoc structured questionnaire.

Measure of quality of life. The Quality of Life-Alzheimer Disease (QoL-AD) scale (30) is designed to assess the patient's quality of life (QoLp) from both the patient's and the caregiver's perspective. It is administered to both patients and caregivers and comprises 13 items that refer to different aspects of the patient's wellbeing. Scores for each item range from 1 (poor) to 4 (excellent), yielding a total score between 13 and 52; the higher the score, the 
better the quality of life. The scale's authors considered that it was valid for patients with MMSE scores $>10$.

Stage of dementia. The criteria applied here were those of the Global Deterioration Scale (GDS). This is a clinical assessment scale designed to determine the stage of a patient's dementia. (31)

Depression in the patient and the caregiver. The Geriatric Depression Scale (GDS-d), in its 15 -item format, (32) was directly and independently administered to both patients and caregivers. The cut-off score for probable depression is 6 .

Anosognosia. The Anosognosia Questionnaire-Dementia (AQ-D) (33) was administered to patients and caregivers. It comprises 30 items that refer to cognitive/functional deficits and personality changes, with each item being rated according to the frequency of occurrence, from 0 (never) to 3 (always). The total score therefore ranges from 0 to 90 , with higher scores being indicative of greater anosognosia. The final score is derived by calculating the difference between caregiver and patient scores. The scale's authors considered that anosognosia was present when this difference is $\geq 32$.

Cognitive assessment of the patient. This was based on MMSE), (29) a brief cognitive assessment whose score ranges from 0 to 30 (the lower the score the greater the cognitive deterioration).

Functional assessment of the patient. This was based on the Disability Assessment for Dementia (DAD), (34) a measure of basic and instrumental ADL. The DAD comprises 40 items and its total score ranges from 40 to 80 (the higher the score the greater the functional capacity).

Behavioral and psychological symptoms of dementia (BPSD). This aspect was assessed by means of the Neuropsychiatric Inventory (NPI), (35) which comprises twelve subscales that assess the frequency and severity of twelve neuropsychiatric symptoms. In the present study 
this assessment was based on information provided by caregivers. Scores range from 0 to 144 , and the higher the score the greater the frequency and severity of behavioral disorders.

Physical and mental health of caregivers. This was assessed using the abbreviated version of the SF-36 Health Survey, (36) a twelve-item instrument whose total score ranges from 12 to 28. It yields two global dimensions, physical and mental, on each of which the possible score ranges from 0 to 100 (the higher the score the better the respondent's health).

Caregiver burden. This was assessed using the Caregiver Burden Interview (CBI), (37) which comprises 22 items that are scored on a Likert scale ranging from 1 (never) to 5 (almost always). The total score therefore ranges between 22 and 110, and the higher the score the greater the burden.

\section{Procedure}

Neurologists from the Dementia Unit identified eligible patients according to the inclusion criteria and determined their degree of dementia in terms of GDS stage. (31) The sample was recruited between January and October 2011. Of the total number of patients who met the inclusion criteria only four families declined to participate.

In the initial study interview the aims of the research were explained to patients and caregivers, and informed consent was obtained from all participants. Patients and their caregivers were then interviewed separately by two psychologists trained in the administration of the respective tests and instruments.

\section{Statistical analysis}

A descriptive analysis was carried out of the clinical and socio-demographic characteristics of the sample, using absolute and relative frequencies for qualitative variables and measures of central trend and dispersion for quantitative variables.

The influence of clinical and socio-demographic variables on the QoL-AD scores of patients and caregivers was analyzed by means of parametric tests [ANOVA $(F)$ and the 
Student's test $(t)$ ], non-parametric tests [Mann Whitney $U(z)$ and Kruskal-Wallis $\left(\chi^{2}\right)$ ], and Pearson $(r)$ and Spearman $\left(r_{s}\right)$ correlations, in accordance with criteria of normality. Pearson's chi-square test was used for categorical variables. When there was a significant difference between two measures Cohen's $(d)$ was calculated in order to determine the effect size.

The degree of agreement between patients and caregivers on the QoL-AD was assessed by calculating the corresponding correlation and the intraclass correlation coefficient (ICC). Discrepancies between patient and caregivers ratings on the QoL-AD were measured by taking into account their absolute scores.

In order to analyze the influence of severity of dementia we compared QoL-AD scores and associated patient and caregiver factors across the different GDS stages.

The patient and caregiver factors that were related to discrepancies in QoL-AD scores were determined through three linear regression analyses using the Enter method (introducing all the variables in a single step). The dependent variables were the QoL-AD scores of the patient and caregiver and the difference between them (patient-caregiver), while the independent variables were the clinical and socio-demographic factors. The coefficient of contribution for each variable was calculated by means of the solution suggested by Guilford and Fruchter: (38) beta coefficient $\mathrm{x}$ the coefficient of correlation with the dependent variable.

Two-step cluster analysis was then used to identify groups of patients with homogeneous characteristics, introducing the patient variables that were significant in the linear regression analysis and comparing the resulting groups.

For hypothesis contrasts the level of statistical significance was set at 0.05 . All data processing and analysis was performed using SPSS version 17.0 for Windows. 


\section{RESULTS}

\section{Description of the sample}

The final study sample comprised 141 patients and their respective caregivers. Twentyfour of the initial cases $(n=165)$ were excluded: in 14 cases only the family caregiver could be interviewed, in one case only the patient could be interviewed, and in nine cases the patient had an MMSE score below 10.

The mean age of patients and caregivers was, respectively, 77.6 years $(\mathrm{SD}=7.2)$ and 63.2 years $(\mathrm{SD}=13.4)$. Eighty-three patients $(58.9 \%)$ and 101 caregivers $(71.6 \%)$ were women. Seventy-five of the caregivers (53.2\%) were spouses and 58 (41.1\%) were a child of the patient. A total of 118 caregivers $(83.7 \%)$ lived with the patient. The socio-demographic data are shown in Table 1.

\section{Clinical data}

Patients. In terms of the severity of dementia, 57 patients $(40.4 \%)$ met the criteria for GDS stage 4, $46(32.6 \%)$ the criteria for GDS stage 5 and $38(27.0 \%)$ the criteria for GDS stage 6. The mean depression score was $3.6(\mathrm{SD}=2.9)$, while the mean anosognosia score was $37.3(\mathrm{SD}=19.9)$. The mean score on the NPI was $29.3(\mathrm{SD}=21.2)$, with the most intense symptoms being apathy $($ mean $=5.7, \mathrm{SD}=4.4)$, irritability $($ mean $=3.6, \mathrm{SD}=4.1)$, anxiety $($ mean $=2.7, \mathrm{SD}=3.6)$ and aggressiveness $($ mean $=2.6, \mathrm{SD}=3.5)$.

Caregivers. The mean score on the $\mathrm{CBI}$ was $51.9(\mathrm{SD}=16.1)$, while that for depression (GDS-d) was $4.6(\mathrm{SD}=3.6)$.

The remaining clinical characteristics of patients and caregivers are presented in Table 2.

\section{Global ratings of the patient's quality of life}

There were significant differences between the QoLp scores of patients (mean $=34.8, \mathrm{SD}$ $=4.9)$ and caregivers $($ mean $=26.6, \mathrm{SD}=5.6)($ Student's $t=14.5, d f=140, \mathrm{p}<0.001 ; d=1.5)$. 
The ICC values were low in relation to measures of both absolute agreement $(\mathrm{ICC}=0.18 ; d f=$ $140,95 \% \mathrm{CI}=-0.12,0.42)$ and consistency $(\mathrm{ICC}=0.35 ; d f=140,95 \% \mathrm{CI}=0.10,0.53)$.

The only socio-demographic variable that showed differences as regards global QoLp scores was caregiver gender, with men giving higher QoL-p ratings than women $($ mean $=28.1$, $\mathrm{SD}=5.4$, vs. mean $=26, \mathrm{SD}=5.6 ;$ Student's $t=2.0, d f=139, \mathrm{p}=0.046 ; d=0.38)$. There were no significant differences in relation to kinship or living arrangements.

\section{Severity of dementia and quality of life}

There were no significant differences in patient reports of QoLp across different GDS stages, whereas caregivers reported poorer QoLp as severity increased. The discrepancy between patient and caregiver scores increased in line with the severity of dementia (GDS stages).

The clinical factors of patients showed a clear deterioration as severity increased, with a reduction in cognitive and functional ability and an increase in neuropsychiatric symptoms on the NPI, especially apathy (Kruskal-Vallis, $\chi^{2}=25.5, d f=2, \mathrm{p}<0.001$ ), disinhibition (KruskalVallis, $\left.\chi^{2}=16.7, d f=2, \mathrm{p}<0.001\right)$ and euphoria (Kruskal-Vallis, $\chi^{2}=16.0, d f=2, \mathrm{p}<0.001$ ).

Among caregivers, increasing severity of dementia was associated with greater depression, burden as well as with poorer mental health (Table 3).

\section{Depression, anosognosia and quality of life according to GDS stage}

Higher depression scores among patients were correlated with poorer perceived QoLp at all GDS stages. Depression in caregivers was also globally correlated with a poorer perception of QoLp by the caregiver, but was not significant at any one GDS stage.

Higher anosognosia scores among patients were correlated with better perceived QoLp, which remained high across the GDS stages. Conversely, for caregivers greater anosognosia in the patient was inversely correlated with QoLp, especially at GDS stages 4 and 5. 
Anosognosia and depression were inversely correlated among patients, especially in the early stages. For caregivers there was a direct correlation between anosognosia and depression, which only reached significance at GDS stage 6.

The common factor among patients and caregivers was the correlation between greater depression and poorer perceived QoLp. The differential factors were the opposing directions of the correlations between anosognosia and QoLp (direct in patients and inverse in caregivers) and between anosognosia and depression (inverse in patients and direct in caregivers) (Table 3).

\section{Multivariate linear regression analysis}

The regression model for QoLp ratings by patients showed that greater anosognosia and less depression were the main variables associated with higher scores. The regression model for caregiver ratings of QoLp showed that better ratings were associated with less caregiver burden and with the following patient factors: less anosognosia, less depression and greater functional ability in ADL (Table 4).

The regression model for the differences in QoLp scores between patients and caregivers revealed that the factors showing the greatest positive discrepancy were anosognosia and the MMSE score; in both cases patients scored higher than caregivers. The factor that showed the greatest negative discrepancy was depression in the patient, with patients scoring lower than caregivers. The only caregiver factor associated with discrepancies was gender, with women scoring lower than men.

\section{Clusters of patients and caregivers: associated factors}

When the patient variables that were significant in the linear regression analysis of differences in QoLp scores were introduced into the two-step clustering procedure, two more homogeneous groups were identified (Table 5). The clusters revealed differences in relation to 
two patient variables, namely QoLp and GDS-d, which did not show differences in the initial analysis based on GDS stages.

Comparison of the two clusters revealed that patients in the first group had a better cognitive status, fewer neuropsychiatric symptoms and greater functional ability. In other words, their capacities were better preserved. However, patients in this first cluster also presented more depression, less anosognosia and gave worse ratings of QoLp, compared to those in the second group.

Caregivers of patients in the first cluster presented less depression, better mental health and less burden, and also gave better ratings of QoLp

\section{DISCUSSION AND CONCLUSION}

\section{Severity of dementia and patients' quality of life}

The results of the study show that patients' own ratings of their quality of life (QoLp) remained stable in GDS stages despite increasing severity of dementia and greater cognitive, functional and behavioral deterioration. By contrast, caregiver ratings of QoLp were more consistent with the clinical data, decreasing as the severity of dementia increased.

The QoLp ratings of less deteriorated patients were more in line with those of caregivers, with the discrepancy becoming greater as the patient deteriorated further. The observed stability in patients' ratings of QoLp $(39,40)$ and the decreasing ratings among caregivers has been widely reported. $(13,20)$

\section{Quality of life of patients in the analysis of clusters}

The cluster analysis identified two groups of patients with different degrees of deterioration. The only difference between the analysis based on GDS stages and the cluster analysis was that the latter revealed significant differences for the patient variables QoLp and 
depression. This indicates that an approach based on the severity of dementia according to GDS stage is valid when the aim is to observe discrepancies between patients and caregivers. However, if we wish to assess how patient scores evolve we should also include the patient variables anosognosia and depression, alongside the variables related to cognitive, functional and behavioral deterioration. In this regard, the cluster analysis identified two groups of patients with different characteristics and perceptions in relation to QoLp ratings.

\section{Depression, anosognosia and quality of life}

The cluster analysis shows that patients with mild deterioration presented less anosognosia, more depression and a QoLp rating that was closer to that of caregivers. This pattern of results was reversed among more deteriorated patients.

The data show that depression in the patient is associated with more negative ratings of QoLp. The influence of depression is one of the most consistent findings in published research. (2-4)

Among patients the presence of anosognosia was associated with better ratings of QoLp and with greater severity. As regards the latter the results are consistent with previous studies that have reported greater anosognosia with greater severity of dementia, older age and more deficits in ADL. $(41,42)$

In the present study, depression and anosognosia were inversely correlated among patients. Previous research has produced contradictory findings regarding the relationship between depression and anosognosia: whereas some authors have reported greater depression among anosognosic patients (42) others have, in line with the present data, found an inverse correlation between depression and anosognosia in the early stages. $(43,44)$

\section{Discrepancies between patient and caregiver ratings of the patient's quality of life}

A number of hypotheses can be put forward to explain the discrepancies between patient and caregiver ratings of the patient's quality of life: 
Adaptation mechanism. The observed stability in patient ratings of QoLp could be an adaptation mechanism. Indeed, the disability paradox, whereby self-concept remains stable despite disabilities, is well documented. (45) Doubts arise, however, in relation to AD because the cognitive deterioration may be severe in the advanced stages of the disease. The suggestion that patient and caregiver perceptions constitute two unique and different views, both potentially valid, could be included within this perspective. $(22,45)$

Amnesic anosognosia. According to this hypothesis the self-evaluation of patients would be based erroneously on information stored in their memory. As their recent memory deteriorates further they would find it increasingly difficult to offer a reliable and up-to-date description of their capacities and health status. (46) Stability in patient ratings of QoL, regardless of their actual cognitive deterioration, would support this observation.

Executive anosognosia. This hypothesis is complementary to the former. The presence of anosognosia would be associated a deficit in executive capacity, i.e. the patient's ability to analyze and evaluate his or her own situation. A lack of awareness of one's deficits would account for the stability in patient ratings of QoLp in advanced stages of dementia. Various authors have pointed out the advisability of relativizing patients' own appraisals of their quality of life when anosognosia is present. (22-24)

Anosognosia, as a factor present in $\mathrm{AD}$, can bring an interesting perspective to the analysis of quality of life. It should be noted, however, that other factors which may affect patient and caregiver ratings of QoLp have also been reported. Noteworthy among these are depression in the patient, (2-4) the family relationship between patient and caregiver, (15-17) the patient's place of residence $(2,3)$ and environmental factors .(18)

If the concept of 'the patient's quality of life' is to be useful in verifying the appropriateness of therapeutic interventions then any evaluation should, as Mack and Whitehouse (1) point out, take into account not only the inherent features of the disease 
(cognitive and functional deterioration) but also associated factors (anosognosia, depression) and contextual aspects (family and social environment).

\section{Conclusions}

1. Patient ratings of QoLp remained stable across the stages of dementia, despite the fact that the clinical data showed a progressive deterioration.

2. Anosognosia was associated with a more positive self-appraisal among patients and its presence increased as $\mathrm{AD}$ evolves. In the early stages of the disease it was inversely correlated with depression.

3. Caregiver ratings of QoLp were lower than those of patients, although the difference between the two was less in the early stages of dementia.

4. Caregiver ratings of QoLp decreased as anosognosia worsened, as the dementia became more severe, and as functional deficits increased.

5. The factors associated with a greater discrepancy between patient and caregiver ratings of QoLp were the severity of dementia, anosognosia, depression and cognitive status in patients, and female gender among caregivers.

Clinical Implications. Patients' own ratings of their quality of life should be complemented with measures of anosognosia and depression. Depression in the patient alongside a greater awareness of deficits (less anosognosia) may lead to a more negative appraisal of QoL, especially in the early stages of the disease. Treatment of such depression in the early stages could lead to an improved perception of quality of life. In the later stages the presence of greater anosognosia may produce an overly positive view of QoL-p, and the patient's report should therefore be complemented with other non-verbal observations, as well as with information provided by the caregiver. Caregiver burden should be assessed at all stages of the disease as it may bias caregiver ratings of quality of life and anosognosia. (47) 
Attention should also be paid to caregivers' needs for practical guidance and emotional support, as such input could lead to a greater understanding and acceptance of their relative's disease.

The study has a number of limitations. Firstly, the educational level of caregivers was low and this may have influenced their (low) ratings of QoLp. A further limitation concerns the lack of data about a possible history of depression in patients, as this would have helped provide a better understanding of the depression factor. Finally, information was lacking about the quality of the previous and current relationship between patients and caregivers, this being an aspect that would likely affect the ratings of QoLp.

This study was conducted within the framework of the project Assessing perceptions of patient quality of life in patients with Alzheimer's disease and their family caregivers over a two-year period, funded by Spain's Ministry of Science and Innovation (Ref. PSI2010-19014). The authors are also grateful for the support given to this study by the town council of Hospitalet de Llobregat. Thanks are due to the psychologists Laura Moreno-Cordón and Vanesa Viñas-Diez for their work in test administration and data collection, and also to the psychiatrist Dr. Joan Vilalta-Franch for his help with methodological and statistical aspects of the study. 


\section{References}

1. Mack JL, Whitehouse PJ: Quality of life in dementia: state of the art- report of the International Working Group for Harmonization of Dementia Drug Guidelines and the Alzheimer's Society satellite meeting. Alzheimer Dis Assoc Disord 2001;15:69-71

2. Hoe J, Katona C, Orrell M, et al: Quality of life in dementia: care recipient and caregiver perceptions of quality of life in dementia: the LASER-AD study. Int J Geriatr Psychiatry $2007 ; 22: 1031-1036$

3. Conde-Sala JL, Garre-Olmo J, Turró-Garriga O, et al: Factors related to perceived quality of life in patients with Alzheimer's disease: the patient's perception compared with that of caregivers. Int J Geriatr Psychiatry 2009; 24:585-594

4. Naglie G, Hogan DB, Krahn M, et al: Predictors of Patient Self-Ratings of Quality of Life in Alzheimer Disease: Cross-Sectional Results from the Canadian Alzheimer's Disease Quality of Life Study. Am J Geriatr Psychiatry 2011; 19:881-890

5. Ready RE, Ott BR, Grace J: Patient versus informant perspectives of Quality of Life in Mild Cognitive Impairment and Alzheimer's disease. Int J Geriatr Psychiatry 2004; $19: 256-265$

6. Missotten P, Squelard G, Ylieff M, et al: Relationship between quality of life and cognitive decline in dementia. Dement Geriatr Cogn Disord 2008; 25:564-572

7. Shin IS, Carter M, Masterman D, et al: Neuropsychiatric symptoms and quality of life in Alzheimer disease. Am J Geriatr Psychiatry 2005; 13:469-474

8. Baquero M, Peset V, Burguera JA, et al: Calidad de vida en la enfermedad de Alzheimer. Rev Neurol 2009; 49:337-342

9. Nakanishi K, Hanihara T, Mutai H, et al: Evaluating the Quality of Life of People with Dementia in Residential Care Facilities. Dement Geriatr Cogn Disord 2011; 32:39-44 
10. León-Salas B, Olazarán J, Muñiz R, et al: Caregivers' estimation of patients' quality of life (QoL) in Alzheimer's disease (AD): An approach using the ADRQL. Arch Gerontol Geriatr 2010; 53:13-18

11. Naglie G, Hogan DB, Krahn M, et al: Predictors of Family Caregiver Ratings of Patient Quality of Life in Alzheimer Disease: Cross-Sectional Results from the Canadian Alzheimer's Disease Quality of Life Study. Am J Geriatr Psychiatry 2011; 19:891-901

12. Karlawish JH, Casarett D, Klocinski J, et al: The relationship between caregivers' global ratings of Alzheimer's disease patients' quality of life, disease severity, and the caregiving experience. Am Geriatr Soc 2001; 49:1066-1070

13. Schiffczyk C, Romero B, Jonas C, et al: Generic quality of life assessment in dementia patients: a prospective cohort study. BMC Neurol 2010; 10:48

14. Schiffczyk C, Jonas C, Lahmeyer C et al: Gender-dependence of substituted judgment on quality of life in patients with dementia. BMC Neurol 2011; 11:118

15. James BD, Xie SX, Karlawish JH: How do patients with Alzheimer disease rate their overall quality of life?. Am J Geriatr Psychiatry 2005; 13:484-490

16. Conde-Sala JL, Garre-Olmo J, Turró-Garriga O, et al: Quality of life of patients with Alzheimer's disease: differential perceptions between spouse and adult child caregivers. Dement Geriatr Cogn Disord 2010; 29:97-108

17. Conde-Sala JL, Garre-Olmo J, Turró-Garriga O, et al: Differential features of burden between spouse and adult-child caregivers of patients with Alzheimer's disease: An exploratory comparative design. Int J Nurs Stud 2010; 47:1262-1273

18. Bicket MC, Samus QM, McNabney M, et al: The physical environment influences neuropsychiatric symptoms and other outcomes in assisted living residents. Int J Geriatr Psychiatry 2010; 25:1044-1054 
19. Crespo M, Bernaldo de Quirós M, Gómez MM, et al: Quality of Life of Nursing Home Residents with Dementia: A Comparison of Perspectives of Residents, Family, and Staff. Gerontologist 2012; 52:56-65

20. León-Salas B, Logsdon RG, Olazarán J, et al: Psychometric properties of the Spanish QoL-AD with institutionalized dementia patients and their family caregivers in Spain. Aging Ment Health 2011; 15:775-783

21. Starkstein SE, Mizrahi R, Garau L: Specificity of symptoms of depression in Alzheimer disease: a longitudinal analysis. Am J Geriatr Psychiatry. 2005; 13:802-807

22. Ready RE, Ott BR, Grace J: Insight and cognitive impairment: effects on quality-of-life reports from mild cognitive impairment and Alzheimer's disease patients. Am J Alzheimers Dis Other Demen 2006; 21:242-248

23. Berwig M, Leicht $\mathrm{H}$, Gertz HJ: Critical evaluation of self-rated quality of life in mild cognitive impairment and Alzheimer's disease--further evidence for the impact of anosognosia and global cognitive impairment. J Nutr Health Aging 2009; 13:226-230

24. Hurt CS, Banerjee S, Tunnard C, et al: Insight, cognition and quality of life in Alzheimer's disease. J Neurol Neurosurg Psychiatry 2010; 81:331-336

25. Orfei MD, Varsi AE, Blundo C, et al: Anosognosia in mild cognitive impairment and mild Alzheimer's disease: frequency and neuropsychological correlates. Am J Geriatr Psychiatry 2010; 18:1133-1140

26. Okonkwo OC, Wadley VG, Griffith HR, et al: Awareness of deficits in financial abilities in patients with mild cognitive impairment: going beyond self-informant discrepancy. Am J Geriatr Psychiatry 2008; 16:650-659

27. American Psychiatric Association: Manual diagnóstico y estadístico de los trastornos mentales, texto revisado (DSM-IV-TR). Barcelona, Masson, 2001 
28. McKhann G, Drachman D, Folstein M, et al: Clinical diagnosis of Alzheimer's disease: report of the NINCDS-ADRDA Work Group under the auspices of Department of Health and Human Services task force on Alzheimer's disease. Neurology 1984; 34:939-944

29. Folstein MF, Folstein SE, McHugh PR: "Mini Mental State". A practical method for grading the cognitive state of patients for the clinician. J Psychiatr Res 1975; 12:189-198

30. Logsdon RG, Gibbons LE, McCurry SM, et al: Assessing quality of life in older adults with cognitive impairment. Psychosom Med 2002; 64:510-519

31. Reisberg B, Ferris SH, De Leon MJ, et al: The Global Deterioration Scale for assessment of primary degenerative dementia. Am J Psychiatry 1982; 139:1136-1139

32. Sheikh JL, Yesavage JA: Geriatric Depression Scale (GDS). Recent evidence and development of a shorter version. Clin Gerontol 1986; 5:165-173

33. Migliorelli R, Teson A, Sabe L, et al: Anosognosia in Alzheimer's disease: a study of associated factors. J Neuropsychiatry Clin Neurosci 1995; 7:338-344

34. Gélinas I, Gauthier L, McIntyre M, et al: Development of a functional measure for persons with Alzheimer's disease: the Disability Assessment for Dementia. Am J Occup Ther $1999 ; 53: 471-481$

35. Cummings JL, Mega M, Gray K, et al: The neuropsychiatric inventory. Comprehensive assessment of psychopathology in dementia. Neurology 1994; 44:2308-2314

36. Ware JE Jr, Kosinski M, Keller SD: A 12-Item Short-Form Health Survey: construction of scales and preliminary tests of reliability and validity. Med Care 1996; 34:220-233

37. Zarit SH, Todd PA, Zarit JM: Subjective burden of husbands and wives as caregiver: a longitudinal study. Gerontologist 1986; 26:260-266

38. Guilford J P, Fruchter B: Fundamental statistics in psychology and education (5th ed.). New York, McGraw- Hill, 1973 
39. Hoe J, Katona C, Roch B, et al: Use of the QOL-AD for measuring quality of life in people with severe dementia--the LASER-AD study. Age Ageing 2005; 34:130-135

40. Selwood A, Thorgrimsen L, Orrell M: Quality of life in dementia--a one-year follow-up study. Int J Geriatr Psychiatry 2005; 20:232-237

41. Kashiwa Y, Kitabayashi Y, Narumoto J, et al: Anosognosia in Alzheimer's disease: association with patient characteristics, psychiatric symptoms and cognitive deficits. Psychiatry Clin Neurosci 2005; 59:697-704

42. Starkstein SE, Jorge R, Mizrahi R, et al: A diagnostic formulation for anosognosia in Alzheimer's disease. J Neurol Neurosurg Psychiatry 2006; 77:719-725

43. Migliorelli R, Teson A, Sabe L, et al: Prevalence and correlates of dysthymia and major depression among patients with Alzheimer ' s disease. Am J Geriatr Psychiatry 1995; $152: 37-44$

44. Sevush S, Leve N: Denial of memory deficit in Alzheimer's disease. Am J Geriatr Psychiatry $1993 ; 150: 748-751$

45. Ettema TP, Dröes RM, de Lange J, et al: The concept of quality of life in dementia in the different stages of the disease. Int Psychogeriatr 2005; 17:353-370

46. Agnew SK, Morris RG: The heterogeneity of anosognosia for memory impairment in Alzheimer's disease: A review of the literature and a proposed model. Aging Ment Health $1998 ; 2: 7-19$

47. Turró-Garriga O, Garre-Olmo J, Vilalta-Franch J, et al: Burden associated with the presence of anosognosia in Alzheimer's disease. Int J Geriatr Psychiatry (published online ahead of print) doi: 10.1002/gps.3824 
TABLE 1. Socio-demographic characteristics of the participants

\begin{tabular}{|c|c|c|c|}
\hline \multicolumn{2}{|l|}{ Patients $(\mathrm{N}=141)$} & \multicolumn{2}{|l|}{ Caregivers $(N=141)$} \\
\hline Age, years & & Age, years & \\
\hline Mean (SD) & $77.6(7.2)$ & Mean (SD) & $63.2(13.4)$ \\
\hline Median (IQR) & $78.5(74.3-82.4)$ & Median (IQR) & $62.7(52.2-76.0)$ \\
\hline Gender, n (\%) & & Gender, n (\%) & \\
\hline Female & $83(58.9)$ & Female & $101(71.6)$ \\
\hline Marital Status, n (\%) & & Marital Status, n (\%) & \\
\hline Married & $95(67.4)$ & Married & $116(82.4)$ \\
\hline Widowed & $43(30.5)$ & Widowed & $4(2.8)$ \\
\hline Single & $3(2.1)$ & Single & $16(11.3)$ \\
\hline Divorced & ----- & Divorced & $5(3.5)$ \\
\hline Level of education, $\mathrm{n}(\%)$ & & Level of education, $\mathrm{n}(\%)$ & \\
\hline Illiterate / no schooling & $59(41.9)$ & Illiterate / no schooling & $22(15.6)$ \\
\hline $1-4$ years & $27(19.1)$ & 1-4 years & $14(9.9)$ \\
\hline $5-8$ years & $39(27.7)$ & $5-8$ years & $48(34.1)$ \\
\hline \multirow[t]{7}{*}{$>8$ years } & $16(11.3)$ & $>8$ years & $57(40.4)$ \\
\hline & & Family relationship, n (\%) & \\
\hline & & Spouse & $75(53.2)$ \\
\hline & & Son / daughter & $58(41.1)$ \\
\hline & & Other relative & $8(5.7)$ \\
\hline & & Living with the patient, $\mathrm{n}(\%)$ & \\
\hline & & Yes & $118(83.7)$ \\
\hline
\end{tabular}

$\mathrm{IQR}=$ Interquartile range 
TABLE 2. Clinical factors of participants

\begin{tabular}{lll}
\hline Patients (N = 141) & Mean (SD) & Median (IQR) \\
\hline QoL-AD (quality of life) & $34.8(4.9)$ & \\
MMSE (cognition) & $17.6(5.9)$ & \\
AQ-D (anosognosia) & $37.3(19.9)$ & \\
$\quad \geq 32$ points, n (\%) & $79(56.0)$ & \\
GDS-d (depression) & $3.6(2.9)$ & $3.0(1.0-6.0)$ \\
$\quad \geq 6$ points, n (\%) & $43(30.5)$ & \\
DAD (function, ADL) & $55.7(10.2)$ & $55.0(47.0-64.5)$ \\
NPI (behavior) & $29.3(21.2)$ & $25.0(13.5-38.5)$ \\
\hline Caregivers (N = 141) & Mean (SD) & Median (IQR) \\
\hline QoL-AD (quality of life of patients) & $26.6(5.6)$ & \\
CBI (burden) & $51.9(16.1)$ & \\
SF-12 (health) & & \\
$\quad \begin{array}{l}\text { Physical } \\
\text { Mental }\end{array}$ & $47.8(11.0)$ & $51.8(40.1-56.2)$ \\
GDS-d (depression) & $42.6(12.8)$ & $46.1(31.2-53.0)$ \\
\hline & $4.6(3.6)$ & $4.0(3.0-7.0)$ \\
\hline
\end{tabular}

$\mathrm{IQR}=$ Interquartile range 
TABLE 3. Quality of life of patients and patient/caregiver factors in relation to GDS stage

GDS $4(n=57) \quad$ GDS $5(n=46) \quad$ GDS $6(n=38)$

\begin{tabular}{|c|c|c|c|c|c|}
\hline & \multirow{2}{*}{$\begin{array}{l}\text { GDS } 4(\mathrm{n}=57) \\
\text { Mean (SD) }\end{array}$} & \multirow{2}{*}{$\begin{array}{l}\text { GDS } 5(n=46) \\
\text { Mean (SD) }\end{array}$} & \multirow{2}{*}{$\begin{array}{l}\text { GDS } 6(n=38) \\
\text { Mean (SD) }\end{array}$} & \multirow[b]{2}{*}{$F / \chi^{2}$} & \multirow[b]{2}{*}{$\mathbf{p}$} \\
\hline & & & & & \\
\hline \multicolumn{6}{|l|}{ QoL-AD } \\
\hline Patients & $35.4(4.8)$ & $34.3(4.5)$ & $34.4(5.5)$ & 0.7 & $0.491^{\mathrm{a}}$ \\
\hline Caregivers & $29.4(5.9)^{\mathrm{c}}$ & $25.6(4.2)$ & $23.6(5.0)^{\mathrm{e}}$ & 15.3 & $<0.001^{\text {a }}$ \\
\hline Patients-Caregivers (diff.) & $7.3(5.8)$ & $8.9(5.2)$ & $10.7(5.9)^{\mathrm{e}}$ & 8.7 & $0.013^{b}$ \\
\hline \multicolumn{6}{|l|}{ Patient factors } \\
\hline MMSE (cognition) & $20.8(4.8)^{\mathrm{c}}$ & $17.2(5.1)^{d}$ & $13.1(5.4)^{\mathrm{e}}$ & 25.6 & $<0.001^{\text {a }}$ \\
\hline NPI (behavior) & $19.3(15.2)^{\mathrm{c}}$ & $32.7(21.6)$ & $40.4(22.1)^{\mathrm{e}}$ & 29.6 & $<0.001^{b}$ \\
\hline DAD (function, ADL) & $65.3(6.4)^{\mathrm{c}}$ & $52.6(5.9)^{d}$ & $44.9(4.2)^{\mathrm{e}}$ & 96.7 & $<0.001^{b}$ \\
\hline GDS-d (depression) & $3.7(2.9)$ & $3.6(2.8)$ & $3.6(3.1)$ & 0.1 & $0.948^{b}$ \\
\hline AQ-D (anosognosia) & $24.6(17.2)^{\mathrm{c}}$ & $41.5(14.9)^{\mathrm{d}}$ & $52.4(16.6)^{\mathrm{e}}$ & 33.9 & $<0.001^{\text {a }}$ \\
\hline
\end{tabular}

\section{Caregiver factors}

\begin{tabular}{lcccrc} 
SF-12 (physical health) & $48.1(10.6)$ & $46.9(11.9)$ & $48.5(10.8)$ & 0.3 & $0.836^{\mathrm{b}}$ \\
SF-12 (mental health) & $45.8(11.8)$ & $41.5(12.4)$ & $39.2(13.9)$ & 7.2 & $\mathbf{0 . 0 2 6}^{{ }^{b}}$ \\
CBI (burden) & $45.0(13.0)^{\mathrm{c}}$ & $56.1(16.6)$ & $57.1(16.3)^{\mathrm{e}}$ & 9.8 & $<\mathbf{0 . 0 0 1}^{\mathrm{a}}$ \\
GDS-d (depression) & $3.4(2.9)$ & $4.9(3.5)$ & $5.8(4.1)^{\mathrm{e}}$ & 9.9 & $\mathbf{0 . 0 0 7}^{\mathrm{b}}$ \\
Hours/day care ADL & $5.3(4.3)^{\mathrm{c}}$ & $6.8(3.5)^{\mathrm{d}}$ & $9.4(3.0)^{\mathrm{e}}$ & 24.8 & $<\mathbf{0 . 0 0 1}^{\mathrm{b}}$ \\
\hline & $\boldsymbol{r} / \boldsymbol{r}_{\boldsymbol{s}} \mathbf{p}$ & $\boldsymbol{r} / \boldsymbol{r}_{\boldsymbol{s}} \mathbf{p}$ & $\boldsymbol{r} / \boldsymbol{r}_{\boldsymbol{s}} \mathbf{p}$ & $\boldsymbol{r} / \boldsymbol{r}_{\boldsymbol{s}}$ & $\mathbf{p}$
\end{tabular}

Correlations in patients

$\begin{array}{lrrrrrrr}\text { AQ-D / QoL-AD } & 0.54 & <\mathbf{0 . 0 0 1} & 0.38 & \mathbf{0 . 0 1 0} & 0.44 & \mathbf{0 . 0 0 7} & 0.31<\mathbf{0 . 0 0 1}^{\text {f }} \\ \text { AQ-D / GDS-d } & -0.46<\mathbf{0 . 0 0 1} & -0.36 & \mathbf{0 . 0 1 6} & -0.32 & 0.050 & -0.34<0.001 \\ \text { QoL-AD / GDS-d } & -0.65<\mathbf{0 . 0 0 1} & -0.57 & <\mathbf{0 . 0 0 1} & -0.56 & <\mathbf{0 . 0 0 1} & -0.61<\mathbf{0 . 0 0 1}^{\text {g }}\end{array}$

Correlations in caregivers

$\begin{array}{lrrrrrrrr}\text { AQ-D / QoL-AD } & -0.48 & <\mathbf{0 . 0 0 1} & -0.39 & \mathbf{0 . 0 0 8} & -0.28 & 0.094 & -0.56<\mathbf{0 . 0 0 1}^{\mathrm{f}} \\ \text { AQ-D / GDS-d } & 0.20 & 0.122 & 0.03 & 0.807 & 0.39 & \mathbf{0 . 0 1 7} & 0.32<\mathbf{0 . 0 0 1}{ }^{\mathrm{g}} \\ \text { QoL-AD / GDS-d } & -0.16 & 0.223 & -0.25 & 0.084 & -0.05 & 0.731 & -0.25 & \mathbf{0 . 0 0 2} \\ \end{array}$

${ }^{\mathrm{a}} F=$ ANOVAs, $(d f=2,138) ;{ }^{\mathrm{b}} \chi^{2}=$ Kruskal-Wallis, $(d f=2)$; Significant with Bonferroni post-hoc $={ }^{\mathrm{c}}$ Contrast GDS 4-5, ${ }^{\mathrm{d}}$ Contrast GDS 5-6, ${ }^{\mathrm{e}}$ Contrast GDS 4-6.

${ }^{\mathrm{f}} r=$ Pearson correlation coefficients, GDS $4(d f=55)$, GDS $5(d f=44)$, GDS $6(d f=36)$, All cases $(d f=$ 139) $;{ }^{\mathrm{g}} r_{s}=$ Spearman's correlation coefficients 
TABLE 4. Multivariate linear regression analysis. QoL-AD of patients, caregivers and

differences

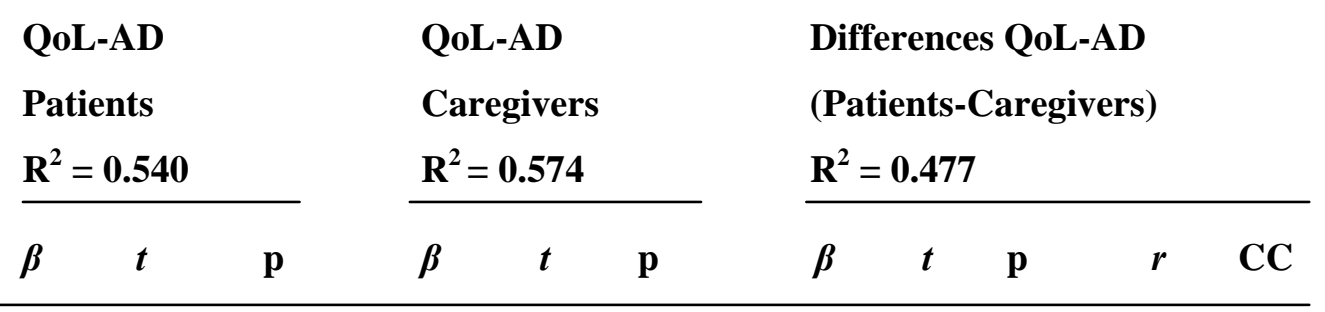

\section{Patient Factors}

$\begin{array}{lcccccccccccc}\text { AQ-D (anosognosia) } & 0.54 & 5.4 & <\mathbf{0 . 0 0 1} & -0.21 & -2.2 & \mathbf{0 . 0 2 9} & 0.50 & 4.6 & <\mathbf{0 . 0 0 1} & 0.63 & \\ 31.9 & & & & & & & & & & & & \\ \text { GDS-d (depression) } & -0.47 & -7.0 & <\mathbf{0 . 0 0 1} & -0.18 & -2.7 & \mathbf{0 . 0 0 6} & -0.17 & -2.4 & \mathbf{0 . 0 1 7} & -0.32 & 5.7 \\ \text { MMSE (cognition) } & 0.15 & 2.3 & \mathbf{0 . 0 2 3} & -0.10 & -1.6 & 0.093 & 0.17 & 2.3 & \mathbf{0 . 0 1 9} & 0.00 & 0.2 \\ \text { NPI (behavior) } & -0.22 & -2.5 & \mathbf{0 . 0 1 1} & -0.10 & -1.2 & 0.209 & 0.00 & 0.0 & 0.988 & 0.40 & 0.0 \\ \text { DAD (function, ADL) } & 0.30 & 3.4 & \mathbf{0 . 0 0 1} & 0.42 & 5.0 & <\mathbf{0 . 0 0 1} & -0.09 & -0.9 & 0.342 & -0.39 & 3.6\end{array}$

\section{Caregiver Factors}

Gender

$$
\begin{array}{lll}
0.05 & 0.8 & 0.386
\end{array}
$$

$-0.05 \quad-0.9 \quad 0.357$

$\begin{array}{lllll}0.14 & 2.1 & \mathbf{0 . 0 3 4} & 0.25 & 3.7\end{array}$

CBI (burden)

$-0.03 \quad-0.4 \quad 0.690$

$-0.19 \quad-2.5 \quad \mathbf{0 . 0 1 2}$

$\begin{array}{lllll}0.07 & 0.8 & 0.389 & 0.36 & 2.6\end{array}$

\section{7}

ANOVA. QoL-AD patients, $F=21.4(d f=7,133), \mathrm{p}<0.001$; QoL-AD caregivers, $F=24.6(d f=7$,

133), $\mathrm{p}<0.001$; Differences QoL-AD, $F=16.6(d f=7,133), \mathrm{p}<0.001$.

$\mathrm{R}^{2}=$ Determination coefficient; $\beta=$ standardized beta coefficient; $r=$ Pearson correlation (zero-order), $d f$

$=139 ; \mathrm{CC}=$ Coefficient of contribution $(\%),[(\beta . r) \times 100]$ 
TABLE 5. Clusters showing significant factors for QoL-AD differences.

\begin{tabular}{|c|c|c|c|c|c|}
\hline & Cl.1, $n=59$ & Cl.2, $n=82$ & & & \\
\hline & Mean (SD) & Mean (SD) & $t / z$ & $\mathbf{p}$ & $d$ \\
\hline QoL-AD & & & & & \\
\hline Patient & $33.4(5.1)$ & $35.7(4.6)$ & 2.7 & $0.007^{\mathrm{a}}$ & 0.47 \\
\hline Caregiver & $30.1(5.1)$ & $24.1(4.6)$ & 7.2 & $<0.001^{\mathrm{a}}$ & 1.23 \\
\hline Patient-Caregiver (diff.) & $4.8(3.7)$ & $11.6(5.3)$ & 7.0 & $<0.001^{b}$ & 1.48 \\
\hline Patient factors & & & & & \\
\hline MMSE (cognition) & $19.7(5.6)$ & $16.0(5.7)$ & 3.7 & $<0.001^{\mathrm{a}}$ & 0.65 \\
\hline NPI (behavior) & $14.6(9.8)$ & $39.9(20.9)$ & 7.8 & $<\mathbf{0 . 0 0 1}{ }^{b}$ & 1.55 \\
\hline $\mathrm{DAD}$ (function, $\mathrm{ADL}$ ) & $62.1(10.0)$ & $51.0(7.5)$ & 6.1 & $<0.001^{b}$ & 1.25 \\
\hline GDS (stage 5-6), n (\%) & $17(28.8)$ & $67(81.7)$ & 37.6 & $<0.001^{\mathrm{c}}$ & \\
\hline GDS-d (depression) & $4.8(3.1)$ & $2.8(2.5)$ & 4.0 & $<0.001^{b}$ & 0.71 \\
\hline$\geq 6$ points, $n(\%)$ & $26(44.1)$ & $17(21.0)$ & 7.4 & $0.006^{c}$ & \\
\hline AQ-D (anosognosia) & $18.8(11.7)$ & $50.5(12.7)$ & 14.8 & $<0.001^{\mathrm{a}}$ & 2.59 \\
\hline$\geq 32$ points, $n(\%)$ & $5(8.8)$ & $74(92.5)$ & 92.1 & $<0.001^{\mathrm{c}}$ & \\
\hline
\end{tabular}

\section{Caregiver factors}

\begin{tabular}{lccccc} 
SF-12 (physical health) & $49.8(9.7)$ & $46.4(11.8)$ & 1.6 & $0.096^{\mathrm{b}}$ & \\
SF-12 (mental health) & $47.0(10.6)$ & $39.4(13.3)$ & 3.6 & $<\mathbf{0 . 0 0 1}^{\text {b }}$ & 0.63 \\
CBI (burden) & $41.4(11.0)$ & $59.4(14.9)$ & 8.2 & $<\mathbf{0 . 0 0 1}^{\text {a }}$ & 1.34 \\
GDS-d (depression) & $3.2(2.6)$ & $5.5(3.9)$ & 3.6 & $<\mathbf{0 . 0 0 1}^{\text {b }}$ & 0.69 \\
$\geq$ 6 points, n (\%) & $9(15.3)$ & $34(41.5)$ & 15.2 & $<\mathbf{0 . 0 0 1}^{\text {c }}$ & \\
Hours/day care & $5.4(4.1)$ & $8.0(3.7)$ & 3.7 & $<\mathbf{0 . 0 0 1}^{\text {b }}$ & 0.66 \\
\hline
\end{tabular}

${ }^{\mathrm{a}} t=$ Student's $t$ test $(d f=139) ;{ }^{\mathrm{b}} z=$ Mann-Whitney $U ;{ }^{\mathrm{c}}$ Pearson chi-square test with Yates' correction (categorical variables), $(d f=1) ; d=$ Cohen's d. 